Working Paper Series

\title{
Positive Trend Inflation and Determinacy in a Medium-Sized New Keynesian Model
}

Jonas E Arias

Guido Ascari

Nicola Branzoli

Efrem Castelnuovo

Working Paper No. 9/18 July 2018 


\title{
Positive Trend Inflation and Determinacy in a Medium-Sized New Keynesian Model*
}

\author{
Jonas E Arias \\ FRB Philadelphia \\ Guido Ascari \\ University of Oxford \\ University of Pavia \\ Bank of Finland \\ Nicola Branzoli \\ Bank of Italy \\ Efrem Castelnuovo \\ Melbourne Institute: Applied Economic \& Social Research, \\ The University of Melbourne \\ Melbourne Institute Working Paper No. 9/18 \\ July 2018
}

\begin{abstract}
*We thank Klaus Adam, Olivier Coibion, Yuriy Gorodnichenko, Jesper Lind'e, Gert Peersman, Mathias Trabandt, Martin Ellison and participants of various seminars, workshops, and conferences for useful feedback. Ascari thanks the MIUR for financial support through the PRIN 07 programme, grant 2007P8MJ7P and the Alma Mater Ticinensis Foundation. Castelnuovo acknowledges financial support by the ARC grant DP160102654. This paper replaces an earlier working paper titled "Monetary Policy, Trend Inflation and the Great Moderation: An Alternative Interpretation -Comment." and another titled "Determinacy Properties of Medium-Sized New-Keynesian Models with Trend Inflation". The views expressed in this paper are those of the authors and do not reflect those of the Bank of Italy, the Federal Reserve Bank of Philadelphia, the Federal Reserve System, or the Bank of Finland. This paper is available free of charge at www.philadelphiafed.org/research-anddata/publications/working-papers. Corresponding author: Jonas E. Arias, Federal Reserve Bank of Philadelphia, Ten Independence Mall, Philadelphia, PA 19106-1574. E-mail: jonasarias@gmail.com
\end{abstract}

Melbourne Institute: Applied Economic \& Social Research

The University of Melbourne

Victoria 3010 Australia

Telephone +61383442100

Fax +61 383442111

Email melb-inst@unimelb.edu.au

Website melbourneinstitute.unimelb.edu.au 


\begin{abstract}
This paper studies the challenge that increasing the inflation target poses to equilibrium determinacy in a medium-sized New Keynesian model without indexation fitted to the Great Moderation era. For moderate targets of the inflation rate, such as 2 or 4 percent, the probability of determinacy is near one conditional on the monetary policy rule of the estimated model. However, this probability drops significantly conditional on model-free estimates of the monetary policy rule based on real-time data. The difference is driven by the larger response of the federal funds rate to the output gap associated with the latter estimates.
\end{abstract}

JEL classification: E52, E3, C22

Keywords: trend inflation, determinacy, monetary policy 
"[...] the most direct attack on low r-star would be for central banks to pursue a somewhat higher inflation target. This would imply a higher average level of interest rates and thereby give monetary policy more room to maneuver [...] Of course, this approach would need to balance the purported benefits against the costs and challenges of achieving and maintaining a somewhat higher inflation rate." John C. Williams (2016), President and Chief Executive Officer of the Federal Reserve Bank of San Francisco

\section{Introduction}

In response to the Great Recession, there has been a call to rethink macroeconomic policy. An element of this proposal is the possibility of increasing the inflation target from 2 to 4 percent; see Blanchard, Dell'Ariccia and Mauro (2010), Krugman (2013), and Ball (2014). The rationale for a higher inflation target is that it would strengthen the capacity of the Federal Reserve to reduce interest rates when economic conditions deteriorate.

Increasing the inflation target, and thereby the level of trend inflation, raises questions about its costs and challenges. This paper focuses on the particular challenge that increasing the inflation target poses to equilibrium determinacy, a key indicator of the underlying ability of central banks to anchor inflation expectations and avoid self-fulfilling economic fluctuations. ${ }^{1,2}$ Previous research by Hornstein and Wolman (2005), Kiley (2007), and Ascari and Ropele (2009) shows that the Taylor principle, which says that central banks should respond more than one for one to inflation, is not enough to guarantee determinacy when trend inflation is positive. More recently, Coibion and Gorodnichenko (2011) provide empirical support for this theoretical finding in the context of a calibrated small-sized New Keynesian model of the U.S. economy. Hirose, Kurozumi and Van Zandweghe (2017) present additional empirical evidence on the failure of the Taylor principle and its implications for the U.S. economy using an estimated small-sized New Keynesian model.

This paper contributes to this literature by examining the relation between positive trend inflation and determinacy in the U.S. through the lens of an estimated medium-sized New Keynesian model, which constitutes the backbone of several DSGE models used for monetary policy analysis.

\footnotetext{
${ }^{1}$ Equilibrium determinacy refers to the existence of a locally unique solution in a linear rational expectations model. Henceforward, we make reference to this equilibrium concept as determinacy. Self-fulfilling fluctuations (also called sunspot shocks) arise when there is indeterminacy, that is, the existence of multiple solutions in a linear rational expectations model.

${ }^{2}$ See Ascari, Phaneuf and Sims (2015) and Blanco (2017) for a comprehensive welfare based analysis of the benefits and costs associated with a higher inflation target.
} 
This class of models includes crucial features to understand business cycle dynamics and the effects of monetary policy - such as capital accumulation, investment adjustment costs, and capital utilization (e.g., Christiano, Eichenbaum and Evans (2005), Smets and Wouters (2007), Justiniano and Primiceri (2008), and Altig et al. (2011)). To this end, we begin by estimating an off-the-shelf version of that class of models by using U.S. data at quarterly frequency for the period 1984Q1-2008Q2, a sample characterized by low inflation and stable economic conditions. Thus, the model provides an empirically credible framework suited to quantitatively investigate the extent to which an increase in trend inflation to 4 percent could lead to self-fulfilling fluctuations in the U.S. economy.

We offer three contributions to the literature. First, we quantify the extent to which the modelimplied probability of determinacy decreases with trend inflation in an estimated medium-sized model. Conditional on our estimated model - and policy rule - an increase in trend inflation to 4 percent would be unlikely to lead the U.S. economy to experience indeterminacy. The probability of determinacy is near one for levels of trend inflation as high as 4 percent - the value suggested by several of the recent proposals to increase the inflation target.

Second, we revisit the relation between the systematic component of monetary policy, trend inflation and determinacy. This is important because the reaction of monetary policy to economic conditions is the main factor underlying the equilibrium properties of New Keynesian models. Despite some quantitative differences, our analysis qualitatively confirms the main lessons of a large literature examining the existence of equilibrium in small-sized New Keynesian models. ${ }^{3}$ These lessons can be summarized as follows: i) the response of the federal funds rate to inflation that is necessary to achieve determinacy is increasing in the level of trend inflation; ii) responding to the output gap is destabilizing, i.e., it leads to indeterminacy; iii) responding to output growth is stabilizing, i.e., it leads to determinacy; iv) monetary policy inertia is stabilizing; and v) when central banks respond to expected inflation, both weak responses as well as strong responses to expected inflation are destabilizing unless there is strong monetary policy inertia. Our simulations show that responding to the output gap is particularly dangerous for determinacy in our estimated model.

Third, we study the model-implied probability of determinacy at each FOMC meeting since the 1970s given the levels of trend inflation and the systematic component of monetary policy that were

\footnotetext{
${ }^{3}$ For a recent survey of this literature, see Ascari and Sbordone (2014).
} 
likely to have prevailed at the time of those meetings, through a series of counterfactuals based on Coibion and Gorodnichenko (2011). Coibion and Gorodnichenko (2011) compute real-time estimates of the Taylor rule, allowing for time-varying coefficients and a time-dependent trend inflation, which then they feed to a calibrated small-sized New Keynesian model. We complement their analysis by feeding their estimates into an estimated medium-sized New Keynesian model.

The resulting time-varying probability of determinacy provides additional evidence to support the view put forward by Clarida, Galí and Gertler (2000) and Lubik and Schorfheide (2004) that the U.S. economy was under indeterminacy during the 1970s and under determinacy in the post-Volcker era. In addition, our simulations show that changes in monetary policy as well as changes in the level of trend inflation play important roles in delivering this outcome - coherently with the results in small-sized models in Coibion and Gorodnichenko (2011) and more recently in Hirose, Kurozumi and Van Zandweghe (2017). In particular, high trend inflation kept the U.S. economy subject to self-fulfilling fluctuations until 1983, despite the switch in policy happening two years earlier, while low trend inflation in the 1990s was a major factor behind the high likelihood of the U.S. economy being in a determinate equilibrium.

The paper is organized as follows. Section 2 presents the model and its estimation. Section 3 examines the relation among determinacy, monetary policy and positive trend inflation in our estimated model. Section 4 revisits the analysis of Section 3 when using real-time measures of the systematic component of monetary policy. Section 5 concludes.

\section{Model and Estimation}

\section{$2.1 \quad$ Model}

The model is taken off the shelf from the New Keynesian literature (Yun (1996), Christiano, Eichenbaum and Evans (2005) and Smets and Wouters (2007)) except that we do not allow for indexation. This assumption is crucial for our analysis, and there are two reasons for our choice. First, there is no strong evidence to support the presence of price or wage indexation; see Coibion and Gorodnichenko (2011) and Christiano, Eichenbaum and Trabandt (2016). Second, this is a standard assumption in the literature studying the macroeconomic effects of positive trend inflation. Because the model is otherwise standard, it suffices for our purposes to briefly describe its main 
features. The economy evolves in discrete time $t$, and it is populated by firms, households, financial intermediaries, and a government.

\subsubsection{Firms}

Final-Good Firms A final good $Y_{t}^{d}$ is produced by final-good firms, using a continuum of intermediate goods $Y_{i t}$, and it is sold to households in a competitive market at a price $P_{t}$. The production function used to produce final goods features constant returns to scale, and it is of the Dixit-Stiglitz form with elasticity of substitution between inputs equal to $\eta_{p}$. The final-good firms purchase inputs $Y_{i t}$ in a monopolistically competitive market at price $P_{i t}$, and they maximize profits subject to a standard CES production function; the optimal demand for each intermediate good is increasing in the quantity of final goods and decreasing with respect to its price, that is:

$$
Y_{i t}=\left(\frac{P_{i t}}{P_{t}}\right)^{-\eta_{p}} Y_{t}^{d}
$$

Intermediate-Good Firms A continuum of intermediate-good firms indexed by $i$ supplies intermediate goods to the final-good firms. When setting prices, intermediate-good firms are subject to a nominal friction in the style of Calvo. In particular, at any given time, a fraction $\nu_{p}$ of them are not able to change prices. Each intermediate-good firm faces the demand function $Y_{i t}$ described above. The production function of intermediate-good producers is Cobb-Douglas with a fixed cost of production $\Phi$ :

$$
Y_{i t}=A_{t}\left(K_{i t-1}^{d}\right)^{\alpha}\left(L_{i t}^{d}\right)^{1-\alpha}-\Phi Z_{t}
$$

The fixed cost is scaled by a composite index of technological progress $Z_{t}=A_{t}^{\frac{1}{1-\alpha}} \mu_{t}^{\frac{\alpha}{1-\alpha}}$, which is determined by the weighted product of a unit root stochastic process for neutral technological change $A_{t}$ and a unit root stochastic process for investment-specific technological change $\mu_{t}$.

Intermediate-good firms face perfectly competitive factor markets. Taking factor prices as given, each firm selects the amount of labor $L_{i t}^{d}$ and capital $K_{i t-1}^{d}$ that minimizes the cost of producing output $Y_{i t}$. Firms are subject to a working capital constraint; they must take a loan from financial intermediaries at a borrowing cost equal to $R_{t-1}$ to pay workers in advance of production. 


\subsubsection{Households}

A continuum of infinitely lived households indexed by $j$ populates the economy. Each household supplies labor $L_{j t}$ to the production sector through a representative labor aggregator that combines labor in the same proportion as firms would do. The optimal demand for each type of labor is proportional to the aggregate labor demand:

$$
L_{j t}=\left(\frac{W_{j t}}{W_{t}}\right)^{-\eta_{w}} L_{t}^{d}
$$

Households supply labor in a monopolistically competitive market at wage $W_{j t}$. When setting wages, they are subject to a nominal friction in the style of Calvo. In particular, at any given time, a fraction $\nu_{w}$ of them are not able to change wages. In addition to supplying labor $L_{j t}$, households consume $C_{j t}$, hold real balances $q_{j t}=Q_{j t} / P_{t}$ (where $Q_{j t}$ stands for nominal balances), and accumulate capital. Households obtain utility from consumption and from holding real balances, and disutility from supplying labor. Households' resources consist of capital income net of capital utilization costs $R_{j t}^{k} K_{j t-1}$, labor income $W_{j t} L_{j t}$, firms' profits $F_{j t} / P_{t}$, net lumpsum transfers from the government $T_{j t} / P_{t}$, revenues from interest earned on money holdings $R_{t-1}\left(M_{j t-1} / P_{t}-Q_{j t} / P_{t}\right)$, and net cash flows obtained by participating in a market for state contingent securities $\bar{A}_{j t} \cdot{ }^{4}$ Households' expenditures consist of consumption, investment in physical capital $X_{j t}$, state contingent securities $\bar{A}_{j t}$ and next period cash $M_{j t}$.

Each household maximizes its utility functional subject to the budget constraint described above. Households' present discounted utility is separable in consumption, labor and real balances, and it is of the form:

$$
\mathbb{E}_{t} \sum_{t}^{\infty} \beta^{t} d_{t}\left[\log \left(C_{j t}-b C_{j t-1}\right)-\psi_{L} d_{L, t} \frac{L_{j t}^{1+\tau}}{1+\tau}+\psi_{q} \frac{q_{j t}^{1-\sigma_{q}}}{1-\sigma_{q}}\right]
$$

The stream of utility is discounted by the subjective discount factor $\beta$. There is habit in consumption governed by the parameter $b$. Labor disutility is a function of the inverse of the Frisch-elasticity of labor denoted by $\tau$. The parameter $\psi_{L}$ is a scale parameter that normalizes hours worked at

\footnotetext{
${ }^{4}$ The net return on capital $\left(R_{j t}^{k}=\left(r_{t}^{k} U_{j t}-\mu_{t}^{-1} a\left(U_{j t}\right)\right)\right)$ consists of two parts: the rate of return of renting capital $r_{t} U_{j t}$ and capital utilization costs $\mu_{t}^{-1} a\left(U_{j t}\right)$ per unit of physical capital. Capital utilization costs are convex as determined by $a\left(U_{j t}\right)=\gamma_{1}\left(U_{j t}-1\right)+\frac{\gamma_{2}}{2}\left(U_{j t}-1\right)^{2}\left(\right.$ with $\gamma_{1}>0$ and $\left.\gamma_{2}>0\right)$.
} 
the steady state. The parameters $\psi_{q}$ and $\sigma_{q}$ do not affect the equilibrium conditions of the model. Utility flows are subject to preference shocks $d_{t}$, and the disutility for labor is subject to shocks $d_{L, t}$, which affect the labor choice decision.

The amount of physical capital available for production evolves according to the following law of motion:

$$
K_{j t}=(1-\delta) K_{j t-1}+\mu_{t}\left(1-S\left(\frac{m_{I t} X_{j t}}{X_{j t-1}}\right)\right) X_{j t}
$$

where $\delta$ is the depreciation rate, $m_{I t}$ is an exogenous stochastic process for the marginal productivity of investment and $S(x)$ is an increasing and convex investment adjustment cost function whose specific functional form is $S(x)=0.5 \kappa\left(x-\Lambda_{z}\right)^{2}$, where $\Lambda_{z}$ denotes the growth rate of the economy at the steady state.

\subsubsection{Financial Intermediaries}

Financial intermediaries receive funds from households by an amount equal to $M_{j t-1}-q_{j t} P_{t}$, and then they lend these funds to intermediate-good firms through intra-period loans, which are in turn used to pay for labor services $L_{t}^{d}$. The interest rate charged on these loans equals $R_{t-1}$.

\subsubsection{Government}

In the model, the Ricardian equivalence holds, and the government issues risk-free bonds $B_{t}$, collects lump-sum taxes $T_{t}$, and purchases final goods by an exogenously amount $G_{t}$. In addition, the government sets the nominal interest rate $R_{t}$ according to a mixed Taylor rule specification as in Coibion and Gorodnichenko (2011):

$\log (R)_{t}=c+\rho_{R_{1}} \log \left(R_{t-1}\right)+\rho_{R_{2}} \log \left(R_{t-2}\right)+\left(1-\rho_{R_{1}}-\rho_{R_{2}}\right)\left(\psi_{\pi} \mathbb{E}_{t} \hat{\Pi}_{t+1}+\psi_{y}\left(\hat{y}_{t}-\hat{y}_{t}^{f p}\right)+\psi_{g y} g y_{t}\right)+\varepsilon_{R, t}$,

where $\log \left(R_{t}\right)$ denotes the $\log$ nominal interest rate, $c$ is a constant equal to $\log \left(R_{s s}\right)\left(1-\rho_{R_{1}}-\rho_{R_{2}}\right)$, and $R_{s s}$ denotes the steady-state nominal interest rate. $\hat{\Pi}_{t}$ denotes the inflation rate in deviations from the inflation target, $\hat{y}_{t}$ denotes $\log$ deviations of output relative to its steady state, $\hat{y}_{t}^{f p}$ denotes $\log$ deviations of output relative to its steady state in the flexible price economy, and $g y_{t}=\hat{y}_{t}-\hat{y}_{t-1}$ denotes the growth rate of output. The flexible price economy is modeled by removing the nominal frictions. 
The nominal interest rate responds to expected future inflation, to the current output gap, and to the current output growth. The magnitudes of these responses are denoted by $\psi_{\pi}, \psi_{y}$, and $\psi_{g y}$, respectively. In addition, monetary policy evolves gradually; the degree of inertia is characterized by the coefficients $\rho_{R_{1}}$ and $\rho_{R_{2}}$. Finally, $\varepsilon_{R, t}$ denotes unexpected monetary policy shocks. Our choice of this Taylor rule specification is based on two grounds. First, we want to compare our results with those obtained by Coibion and Gorodnichenko (2011). Second, there are studies, Coibion and Gorodnichenko (2012) and Ascari, Castelnuovo and Rossi (2011), showing that this specification is the best fitting among a number of alternatives for the post-World War II U.S. data.

\subsubsection{Market Clearing and Exogenous Stochastic Processes}

The aggregate market-clearing condition implies that production equals aggregate demand scaled by price dispersion $v_{p t}, Y_{t}=v_{p t} Y_{t}^{d}$. In addition, labor and capital markets clear, i.e., $\int L_{j, t}^{d} d j=L_{t}^{d}$ and $\int K_{i, t-1} d i=K_{t-1}^{d}$.

To conclude, Table 1 specifies the stochastic processes for the exogenous variables in log deviations from the steady state; that is, for each variable $x$, we describe the law of motion of $\hat{x}_{t}=\log \left(x_{t}\right)-\log \left(x_{s s}\right)$. In addition, we let $\tilde{x}$ denote $\tilde{x}_{t}=\frac{x_{t}}{x_{t-1}}$.

\begin{tabular}{ll}
\hline \hline Variable & Stochastic Process \\
\hline Preference shock & $\hat{d}_{t}=\rho_{d} \hat{d}_{t-1}+\sigma_{d} \varepsilon_{d, t}$ \\
Labor preference shock & $\hat{d}_{L, t}=\rho_{d_{L}} \hat{d}_{L, t-1}+\sigma_{d_{L}} \varepsilon_{d_{L}, t}$ \\
Neutral technological progress & $\hat{\tilde{a}}_{t}=\left(1-\rho_{\tilde{A}}\right) \log \left(\Lambda_{\tilde{A}}\right)+\rho_{\tilde{A}} \hat{\tilde{a}}_{t-1}+\sigma_{A} \varepsilon_{\tilde{A}, t}$ \\
Marginal productivity of investment & $\hat{m}_{I, t}=\rho_{m_{I}} \hat{m}_{I, t-1}+\sigma_{m_{I}} \varepsilon_{m_{I}, t}$ \\
Investment-specific technological progress & $\hat{\tilde{\mu}}_{t}=\left(1-\rho_{\tilde{\mu}}\right) \log \left(\Lambda_{\tilde{\mu}}\right)+\rho_{\tilde{\mu}} \tilde{\tilde{\mu}}_{t-1}+\sigma_{\tilde{\mu}} \varepsilon_{\tilde{\mu}, t}$ \\
Government spending & $\hat{g}_{t}=\rho_{G} \hat{g}_{t-1}+\sigma_{G} \varepsilon_{G, t}$ \\
\hline
\end{tabular}

Table 1: Exogenous stochastic processes 


\subsection{Estimation}

When studying the equilibrium determinacy of New Keynesian models in the absence of indexation, it is common to work with small-sized calibrated models. ${ }^{5}$ The appeal of such an approach is that in these cases, determinacy can be characterized either analytically (e.g., Ascari and Ropele (2009)) or numerically by a small number of parameters (e.g., Coibion and Gorodnichenko (2011)). Unfortunately, the addition of capital and other typical features of New Keynesian models used for policy analysis - such as capital adjustment costs, capital utilization, sticky wages, and the systematic component of monetary policy - implies that determinacy can no longer be characterized analytically and that it becomes a complicated function of a larger number of structural parameters.

Motivated by the complexity of characterizing determinacy in this type of models, we take a pragmatic approach. Specifically, we estimate the model described in Section 2.1 using quarterly U.S. data for the period 1984Q1-2008Q2 and use the estimation results to discipline our analysis of determinacy. The variables included in the estimation are real GDP growth, real consumption growth, real investment growth, hours worked, the nominal interest rate, GDP deflator inflation, and real wage inflation. Because our estimation procedure closely follows the literature, we relegate details to Appendix A.1.

\begin{tabular}{|c|c|c|c|c|c|c|c|}
\hline \multirow{2}{*}{ Parameters } & \multicolumn{4}{|c|}{ Posterior } & \multicolumn{3}{|c|}{ Prior } \\
\hline & Mode & Mean & 5 Percent & 95 Percent & Distribution & Mean & Std \\
\hline$\psi_{\pi}$ & 2.28 & 2.39 & 1.93 & 2.89 & Gamma & 1.70 & 0.30 \\
\hline$\psi_{y}$ & 0.01 & 0.02 & 0.00 & 0.07 & Gamma & 0.13 & 0.10 \\
\hline$\psi_{g y}$ & 0.52 & 0.53 & 0.31 & 0.77 & Gamma & 0.13 & 0.10 \\
\hline$\rho_{R 1}$ & 1.29 & 1.27 & 1.15 & 1.38 & Normal & 1.00 & 0.20 \\
\hline$\rho_{R 2}$ & -0.43 & -0.42 & -0.52 & -0.31 & Normal & 0.00 & 0.20 \\
\hline$\kappa$ & 3.98 & 4.13 & 2.90 & 5.56 & Gamma & 3.00 & 0.75 \\
\hline$b$ & 0.82 & 0.82 & 0.71 & 0.90 & Normal & 0.15 & 0.05 \\
\hline$\left(\eta_{p}-1\right)^{-1}$ & 0.26 & 0.25 & 0.19 & 0.31 & Normal & 0.15 & 0.05 \\
\hline$\left(\eta_{w}-1\right)^{-1}$ & 0.20 & 0.20 & 0.13 & 0.27 & Gamma & 2.00 & 0.75 \\
\hline$\tau$ & 1.13 & 1.51 & 0.78 & 2.45 & Gamma & 0.25 & 0.10 \\
\hline$\nu_{p}$ & 0.82 & 0.81 & 0.78 & 0.85 & Beta & 0.50 & 0.20 \\
\hline$\nu_{w}$ & 0.58 & 0.56 & 0.42 & 0.69 & Beta & 0.50 & 0.20 \\
\hline
\end{tabular}

Table 2: Estimated Structural Parameters

\footnotetext{
${ }^{5}$ An exception is Carlstrom and Fuerst (2005) who work with a medium-sized calibrated New Keynesian model.
} 

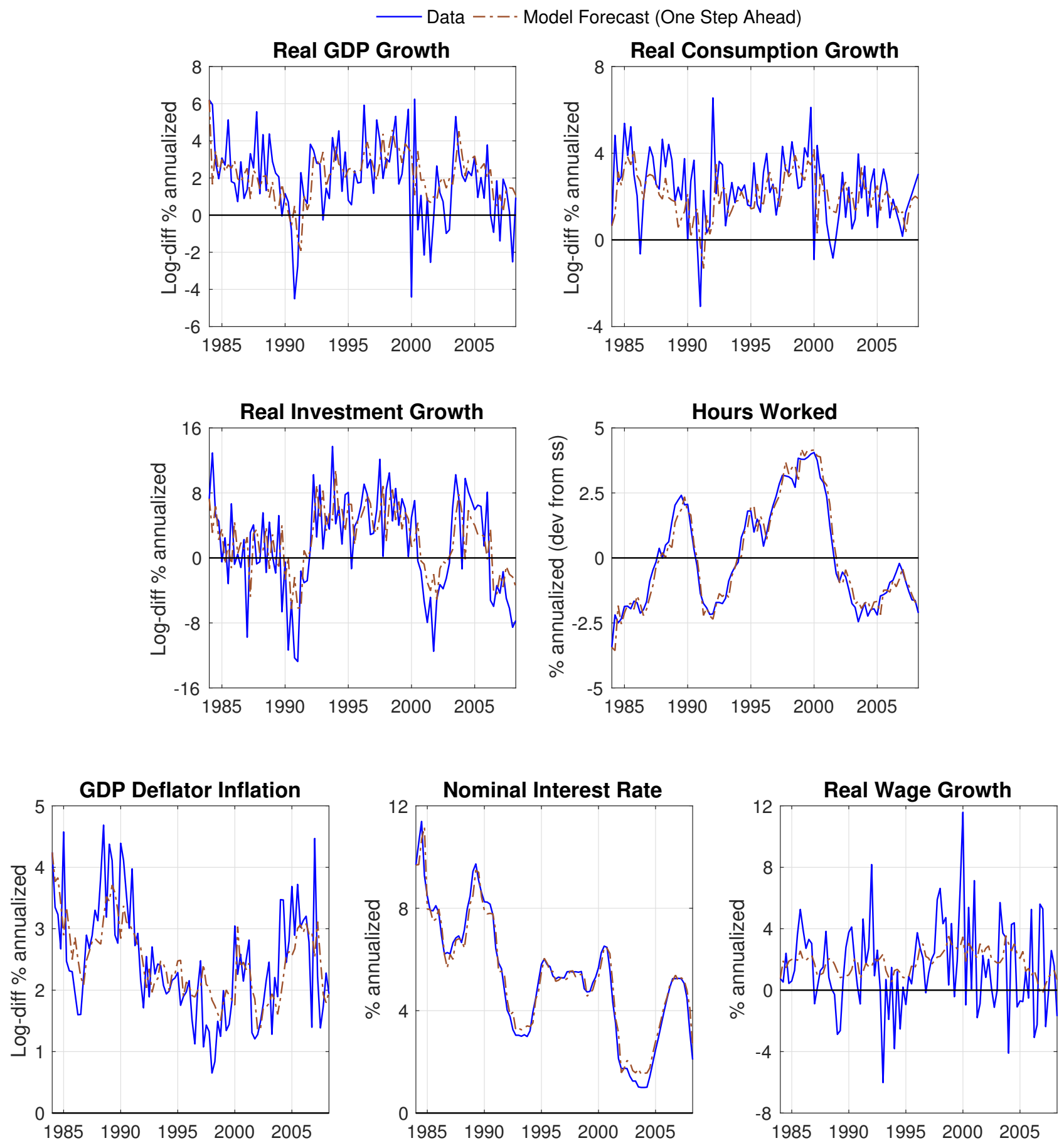

Figure 1: One-Step-Ahead Forecasts

While we estimate most of the model parameters, some of them are calibrated. The steady-state level of inflation is set equal to 1.0061 , which is equal to 2.5 percent in annualized terms (the average in our sample). The subjective discount factor $\beta$ is set equal to 0.9979 to match the average real interest rate in our sample. The capital share of the economy $\alpha$ and the depreciation rate of capital $\delta$ are set equal to 0.225 and 0.025 , respectively, based on Schmitt-Grohe and Uribe 
(2012). The steady-state level of government purchases over GDP, $\eta_{G}$, is set equal to 0.2 , which is the average in our sample. The growth rate of the economy at the steady-state $\Lambda_{Z}$ is set equal to 1.0048, which matches the average growth rate of the economy in our sample. Similarly, the steady-state growth rate of the investment-specific shock $\Lambda_{\mu}$ is set equal to 1.0060, which is calibrated to match the average relative price of investment in terms of consumption in our sample using Justiniano, Primiceri and Tambalotti's (2011) data. The inverse of the elasticity of substitution of capital utilization with respect to the rental rate of capital $\sigma_{a}$ is not well identified, and it is set equal to 1.1739 following Smets and Wouters (2007). We set the autocorrelation of the unit root investment-specific technological progress $\rho_{\tilde{\mu}}$ equal to zero given that the autocorrelation of the marginal efficiency of investment, $\rho_{m_{I}}$, already captures autocorrelation in investment shocks. The volatility of the unit root process for investment-specific technological change $\sigma_{\tilde{\mu}}$ does not have good convergence properties; hence, we set it equal to the posterior mode that would be obtained when $\sigma_{\tilde{\mu}}$ is treated as one of the estimated parameters.

Table 2 shows the posterior mode, the posterior mean and the 90 posterior percent credible sets of the estimated structural parameters of the model. Our estimates are in line with the literature; therefore, for ease of exposition, we discuss them in Appendix A.2. ${ }^{6}$

Figure 1 plots the data and the respective model implied one-step-ahead forecasts when the parameters are evaluated at the posterior mode. In particular, starting at the initial values of 1984Q1, we compute $\mathbb{E}\left(\mathbf{x}_{(t+1)} \mid \mathcal{Y}_{t}\right)$ for $t=1984 \mathrm{Q} 1, \ldots, 2008 \mathrm{Q} 2$, where $\mathbf{x}_{t}$ denotes each of the observables used in the estimation and where $\mathcal{Y}_{t}$ denotes the agents' information set at time $\mathrm{t}$. Overall, our model is able to track the evolution of key macroeconomic variables.

\section{Determinacy and Positive Trend Inflation}

In this section, we examine the relation between determinacy and positive trend inflation. First, we use our estimated medium-sized model to quantify the extent to which the ability of central banks to induce determinacy - a key indicator of the underlying ability of central banks to anchor inflation expectations and avoid self-fulling economic fluctuations - is undermined at high values of trend inflation. Second, we analyze how the systematic component of monetary policy affects determinacy in the presence of positive trend inflation.

\footnotetext{
${ }^{6}$ Table A.2.1 in Appendix A.3 presents the estimated parameters for the exogenous stochastic processes.
} 


\subsection{Probability of Determinacy}

Let's begin by quantifying the probability of determinacy implied by our model by drawing from the posterior distribution of the estimated parameters and assessing whether there is determinacy at different levels of trend inflation. Specifically, the probability of determinacy at a given level of trend inflation $\bar{\Pi}$ is computed as follows:

$$
\operatorname{Pr}(\text { Determinacy } \mid \bar{\Pi})=\frac{\sum_{i=1}^{n} \mathbf{1}_{d}(\theta(i), \bar{\Pi})}{n},
$$

where $\theta(i)$ denotes the i-th draw of the posterior distribution of the estimated parameters $\theta, n$ denotes the number of posterior draws, and $\mathbf{1}_{d}(\theta(i), \bar{\Pi})$ equals one when the solution to the model evaluated at $(\theta(i), \bar{\Pi})$ is determinate and zero otherwise. Note that we take into account the estimation uncertainty associated with the systematic component of monetary policy as well as with the remaining structural parameters.

Figure 2 shows the probability of determinacy associated with levels of trend inflation between 0 and 10 percent. $^{7}$ The probability of determinacy equals one when trend inflation equals zero. As the level of trend inflation increases, the probability of determinacy remains near one for values of trend inflation as high as 3 percent, which is a value higher than the average inflation rate realized over the period 1984Q1-2008Q2. As trend inflation increases above 3 percent, the probability of determinacy begins to decline. However, the probability of determinacy is above 0.9 for values of trend inflation as high as 5 percent, which is 1 percentage point higher than the 4 percent level associated with the majority of the proposals to raise the inflation target. For values of trend inflation above 5 percent, the probability of determinacy declines sharply with trend inflation: it drops to about 0.7 for the value of trend inflation equal to the average inflation in the U.S. during the period 1975-1981 (i.e., 6.6 percent) and is below 0.2 when trend inflation equals 10 percent.

Two results stand out. First and foremost, Figure 2 documents that ceteris paribus trend inflation negatively affects determinacy in a medium-sized model. To the best of our knowledge, we are the first to show that this result, usually obtained in small-sized New Keynesian models, holds in a medium-sized model embedding the key features of models used in central banks for policy analysis and forecasting. Second, Figure 2 suggests that conditional on our estimated policy

\footnotetext{
${ }^{7}$ The choice of 10 percent as an upper bound is motivated by Gagnon (2009), who finds evidence of strong state price dependence for levels of trend inflation higher than 10 percent.
} 


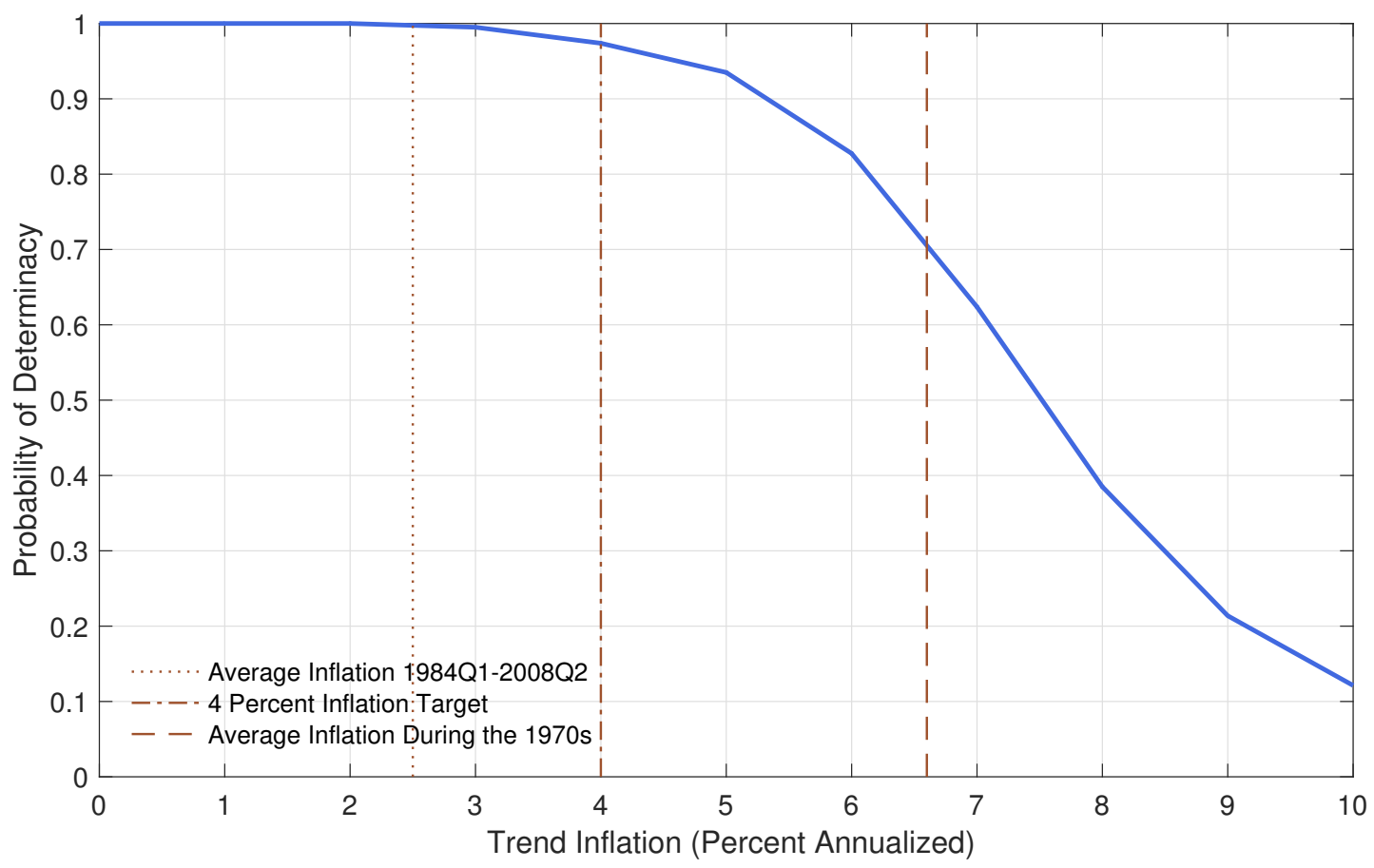

Figure 2: Probability of Determinacy and Trend Inflation

rule for the Great Moderation period, an increase in trend inflation to 4 percent would be unlikely to lead the U.S. economy to experience indeterminacy.

Importantly, these results depend on our estimated monetary policy rule, which corresponds to the Great Moderation, a period of active monetary policy (see e.g., Lubik and Schorfheide (2004)). To emphasize the importance of active monetary policy, we re-compute the probability of determinacy by considering simulations in which the posterior draws associated with the monetary policy rule of our model are replaced by the parameters of the monetary policy rule estimated by Coibion and Gorodnichenko (2011) for the pre-Volcker era, a period often associated with passive or accommodative monetary policy and indeterminacy.

Figure 3 reports the results from these simulations. The solid line replicates the probability of determinacy implied by our estimated model shown in Figure 2. The dashed line marked with circles shows the probability of determinacy implied by our estimated model when all the parameters of the monetary policy rule are set to Coibion and Gorodnichenko's (2011) point estimates for the pre-1979 period. Such point estimates are 1.04, 0.52/4, and 0 for the response to expected inflation, the output gap, and output growth, respectively, and 1.34 and -0.44 for the coefficients describing the degree of monetary policy inertia. The probability of determinacy 
implied by the pre-1979 monetary policy rule is equal to zero for all the levels of trend inflation under analysis. This is consistent with the view, put forward by Clarida, Galí and Gertler (2000), that passive monetary policy led the U.S. economy to indeterminacy during the pre-1979 period.

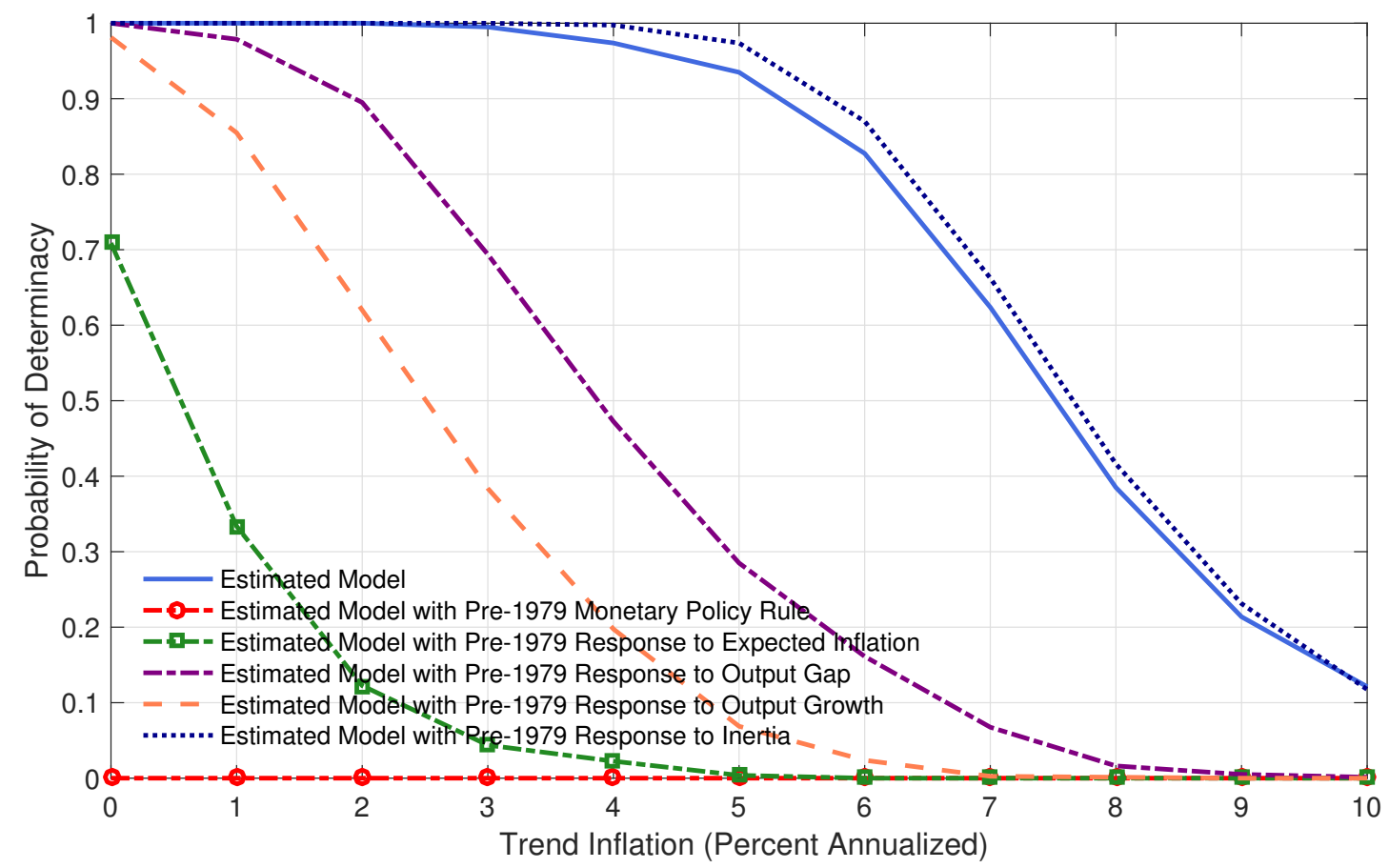

Figure 3: Probability of Determinacy and Trend Inflation

To understand the stark difference between the probability of determinacy implied by our estimated policy rule and that implied by the pre-1979 monetary policy rule, it is insightful to consider the systematic components of monetary policy one at a time. Accordingly, the dashed line marked with squares shows the probability of determinacy implied by our estimated model when we change the response to expected inflation in our estimated rule by setting it equal to the pre-1979 monetary policy rule. The probability of determinacy equals 0.7 when trend inflation equals zero, and it exponentially decreases toward zero as trend inflation increases. In fact, the probability of determinacy at a level of trend inflation equal to 4 percent is almost zero. Note that the response to expected inflation estimated by Coibion and Gorodnichenko (2011) for the pre-1979 monetary policy rule (1.04) is substantially lower than our posterior mode estimate of 2.28 and lies below the 90 percent credible set equal to $[1.93,2.89]$. The dashed-dotted line shows the probability of determinacy implied by our estimated model when the response to the output 
gap is set equal to the pre-1979 monetary policy rule. As was the case when switching the response to expected inflation, a switch in the response to the output gap also implies a lower probability of determinacy at all the levels of trend inflation under analysis. In this case, the pre-1979 response to the output gap $(0.52 / 4)$ is greater than the 90 percent credible set $[0.00,0.07]$ resulting from the posterior estimates of our model. The dashed line shows the probability of determinacy implied by our estimated model when the response to output growth is set equal to the pre-1979 monetary policy rule. As was the case above, this simulation implies a lower probability of determinacy for all the levels of trend inflation under analysis. The pre-1979 response to the output growth (0) is smaller than the 90 percent credible set [0.31,0.77] associated with our Great Moderation estimates. Finally, the dotted line shows the probability of determinacy implied by our estimated model when the parameter describing the monetary policy inertia is set equal to the pre-1979 monetary policy rule. In contrast to the previous cases, the probability of determinacy is higher than the probability implied by our estimated model. This is because the pre-1979 overall policy inertia $(0.90=1.34-0.44)$ is slightly higher than the posterior mean associated with our Great Moderation estimates, 0.86 .

In sum, we find that in a medium-sized New Keynesian model fitting the behavior of standard macroeconomic variables for the Great Moderation, an increase in trend inflation to 4 percent does not create a significant risk of self-fulfilling fluctuations for the U.S. economy. However, conditional on Coibion and Gorodnichenko's (2011) estimated rule for the pre-1979 period, the U.S. economy would have experienced indeterminacy for any level of positive trend inflation. Thus, consistent with previous studies, our results suggest that monetary policy in the 1970s could have been the cause of self-fulfilling fluctuations and thus the main source of the Great Inflation. It follows that the role of trend inflation crucially depends on a particular policy in place. In particular, our simulations show that a higher response to expected inflation, a lower response to the output gap, a higher response to output growth and a higher inertia in the monetary policy rule diminish the probability of determinacy for any given level of trend inflation. This calls for a deeper investigation of the relationship among monetary policy, trend inflation, and determinacy. This is what we turn to next. 


\subsection{Monetary Policy, Determinacy and Trend Inflation}

A large number of studies have explored the relation between equilibrium determinacy and positive trend inflation in small-sized New Keynesian models, as recently reviewed by Ascari and Sbordone (2014). The main lessons of this line of research that can be summarized as follows: i) the response of the federal funds rate to inflation (current or expected) that is necessary to achieve determinacy is increasing in the level of trend inflation; ii) responding to the output gap is destabilizing, i.e., it leads to indeterminacy; iii) responding to output growth helps determinacy; iv) monetary policy inertia is also stabilizing; and v) when central banks respond to expected inflation, weak responses as well as strong responses to expected inflation are destabilizing unless there is strong monetary policy inertia.

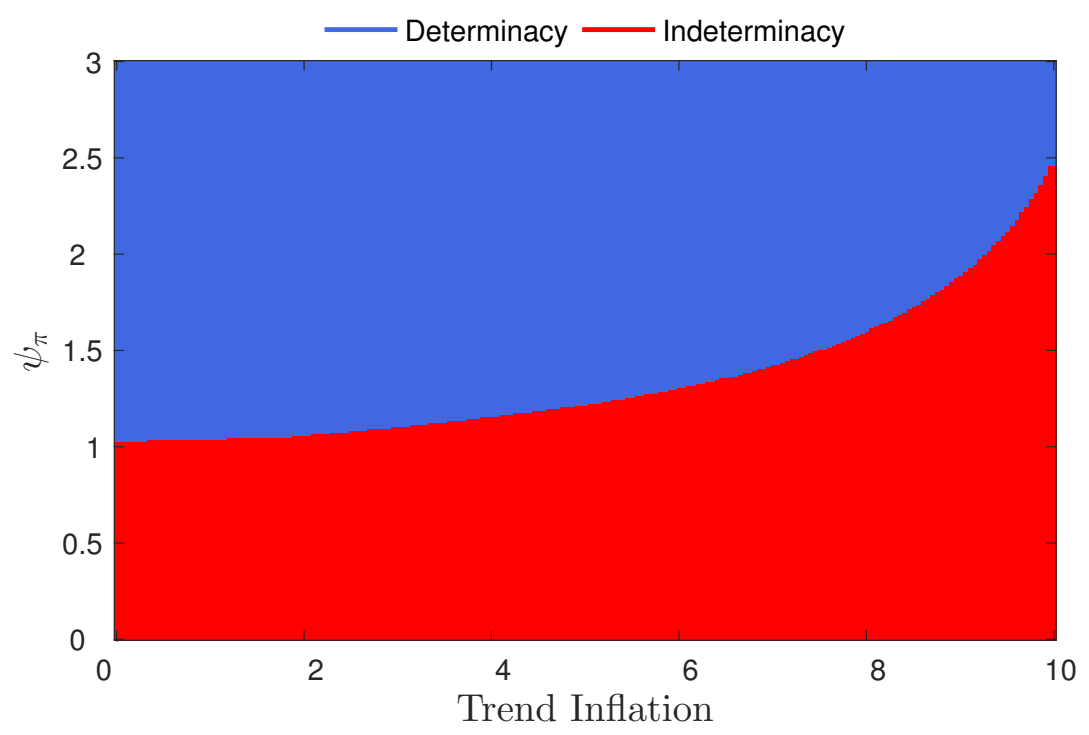

Figure 4: Response to Inflation, Trend Inflation and Determinacy

In line with the previous literature for small-sized models, we investigate the determinacy regions of the parameter space to scrutinize these findings in our estimated medium-sized model. Figures 4 and 5 plot the determinacy and indeterminacy regions when varying the policy parameters or the level of trend inflation. ${ }^{8}$ In particular, Figure 4 characterizes the equilibrium of the model as a function of trend inflation and the response of the federal funds rate to inflation. Figure 5 shows how the systematic components of monetary policy affect determinacy at different values of trend inflation: In Panel (a), trend inflation equals 2.5 percent annualized (the average during the Great

\footnotetext{
${ }^{8}$ Determinacy areas are depicted in blue and indeterminacy areas are depicted in red.
} 

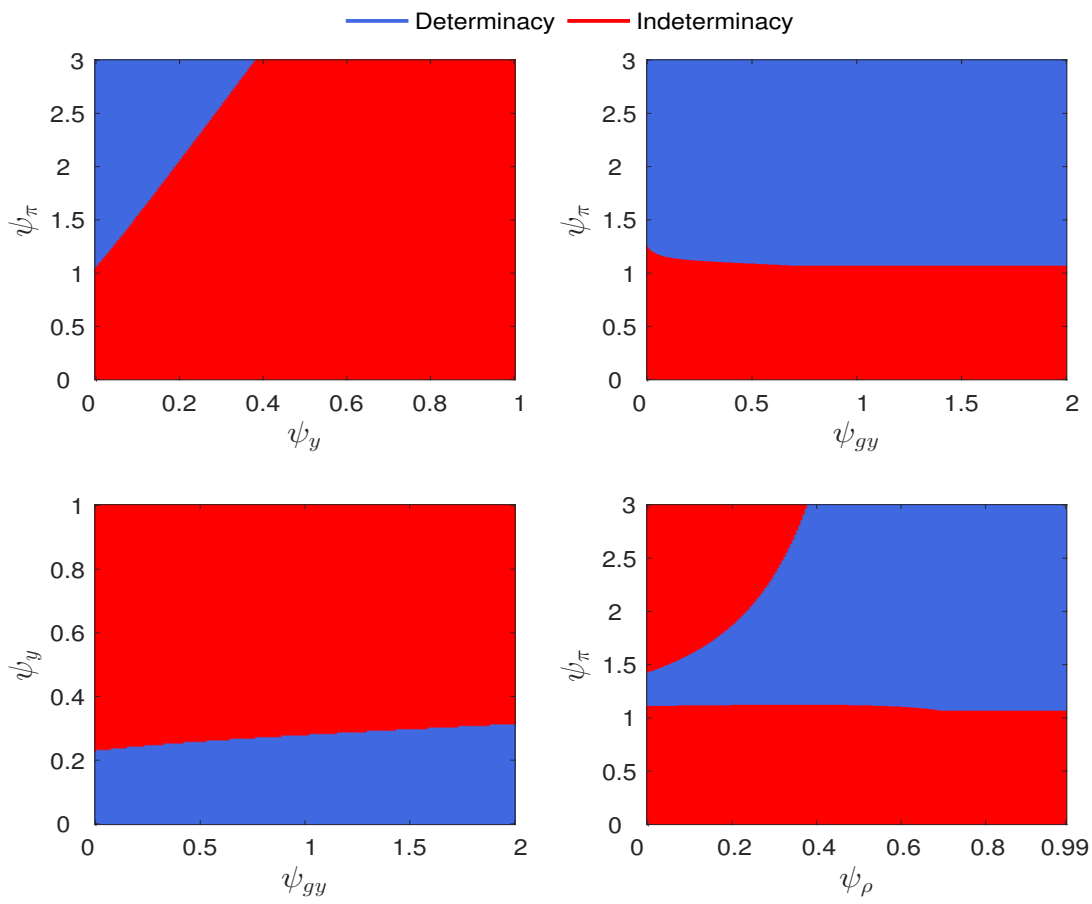

(a) Trend inflation equals 2.5 percent annualized
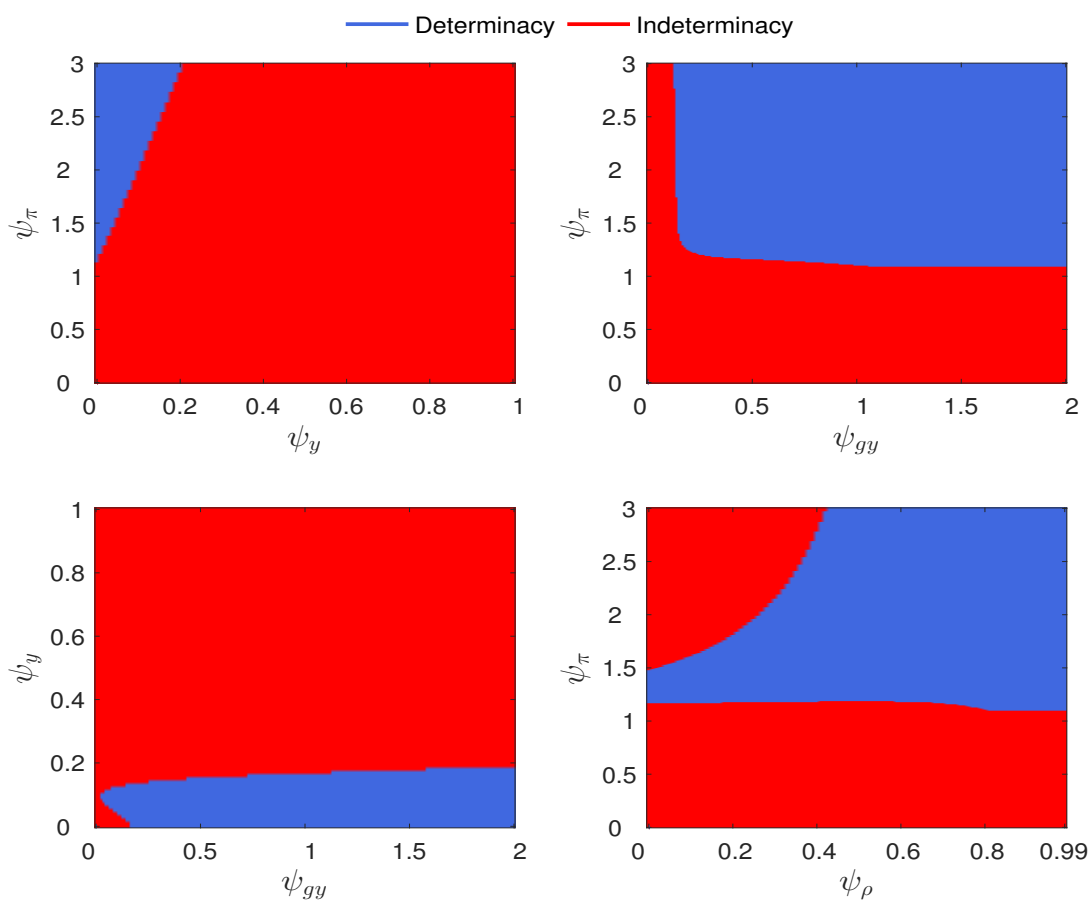

(b) Trend inflation equals 4 percent annualized

Figure 5: Panel (a) shows how the systematic components of monetary policy affect determinacy when trend inflation equals the average level observed during the Great Moderation (about 2.5 percent annualized). Panel (b) shows how the systematic components of monetary policy affect determinacy when trend inflation equals 4 percent, as recently considered by Blanchard, Dell'Ariccia and Mauro (2010), Krugman (2013), and Ball (2014). 
Moderation era); in Panel (b), trend inflation equals 4 percent annualized (in line with the recent suggested increase in the inflation target). More specifically, the upper left subplot in Panel (a) describes determinacy as a function of the response of the federal funds rate to expected inflation $\left(\psi_{\pi}\right)$ and to the output gap $\left(\psi_{y}\right)$, and the remaining parameters are fixed at their posterior mode and calibrated values, respectively. Henceforward, unless stated otherwise, when considering the effects of certain parameters on determinacy, the remaining parameters are fixed in this manner. The upper right subplot repeats the analysis focusing on the response of the federal funds rate to expected inflation $\psi_{\pi}$ and to output growth $\psi_{g y}$. The lower left subplot describes determinacy as a function of $\psi_{y}$ and $\psi_{g y}$. The lower right panel shows determinacy when varying the response to expected inflation and the degree of monetary policy inertia $\psi_{\rho} \equiv \psi_{\rho_{R_{1}}}+\psi_{\rho_{R_{2}}}$. Panel (b) replicates Panel (a) when trend inflation is set to 4 percent annualized. Note that, as expected, the determinacy regions shrink with trend inflation in all the panels. Based on these figures, we now revisit the role of the systematic components of monetary policy in our estimated model.

As in small-sized models, Figure 4 shows that the response of the federal funds rate to inflation that is necessary to achieve determinacy is increasing in the level of trend inflation. This effect seems, however, to be less pronounced than the one reported in most small-sized New Keynesian models. ${ }^{9}$

Next, we consider the destabilizing effect of responding to the output gap. The upper left subplots in Panels (a) and (b) of Figure 5 show that the determinacy region substantially shrinks as the response to the output gap increases. When the policy rule does not respond to the output gap, then a level of $\psi_{\pi}$ that satisfies the Taylor principle $\left(\psi_{\pi}>1\right)$ is sufficient to guarantee determinacy. However, very small positive values of $\psi_{y}$ require a very strong increase in $\psi_{\pi}$ to guarantee determinacy, even when trend inflation is as low as 2 or 4 percent. This contrasts some findings for small-sized New Keynesian models, in which small but positive responses to the output gap lead to lower minimum responses to inflation to achieve determinacy, as in the case with zero trend inflation (see Coibion and Gorodnichenko (2011), p. 349).

While large responses to the output gap lead to indeterminacy, responding to output growth is stabilizing. The upper right subplot of Panel (b) in Figure 5 shows that for typical responses to inflation such as those near 1.5, the model becomes determinate as the response to output growth increases. A similar conclusion arises by examining the lower left subplots in Panels (a) and (b) of

\footnotetext{
${ }^{9}$ See Coibion and Gorodnichenko (2011) and Ascari and Sbordone (2014).
} 
Figure 5: as the response to output growth increases, equilibrium determinacy is possible even with somewhat larger responses to the output gap. However, this effect is relatively small: responding to output growth has very limited power to counterbalance the destabilizing effects of responding to the output gap.

We conclude by revising the role of monetary policy inertia. The lower right subplots in Panels (a) and (b) of Figure 5 show that as the degree of monetary policy inertia increases, there is a wider range of responses of the federal funds rate to expected inflation that are consistent with determinacy. In addition, given that our monetary policy rule reacts to expected inflation, in the absence of substantial monetary policy inertia, weak as well as strong responses to expected inflation can lead to indeterminacy, consistent with King (2000) and Carlstrom and Fuerst (2005).

In sum, the main lessons on the relation among systematic monetary policy, determinacy, and positive trend inflation derived from small-sized New Keynesian models qualitatively hold on a medium-sized estimated New Keynesian model that includes the typical features relevant for monetary policy analysis. There are some quantitative differences though, most notably that the destabilizing effect of responding to the output gap is very strong even for quite low levels of trend inflation.

\section{Monetary Policy and Trend Inflation Since the 1970s}

\subsection{Probability of Determinacy and Monetary Policy in Real Time}

The previous section revolves around assessing the probability of determinacy conditional on the monetary policy parameters estimated for the Great Moderation period. A common concern of such an approach is that the estimated parameters for the monetary policy rule may not represent the true response of policymakers to economic conditions at the time of each FOMC meeting. For instance, Orphanides (2002) and Orphanides and Williams (2006) highlight the importance of using real-time measures of expected inflation, output growth, and the output gap to obtain an accurate characterization of the systematic component of monetary policy.

We address such concerns by computing the model-implied probability of determinacy at each FOMC meeting since the 1970s given the systematic component of monetary policy and the levels of trend inflation that were likely to have prevailed at the time of those meetings. 
We begin by computing the probability of determinacy at the time of each FOMC meeting using Coibion and Gorodnichenko's (2011) real-time and time-varying estimates for the systematic component of monetary policy and their smooth estimates for trend inflation. We do this by drawing from the distribution of time-varying monetary policy parameters and trend inflation; essentially, we replicate the time-varying inflation case shown in Figure 4 of Coibion and Gorodnichenko (2011) using our estimated medium-sized New Keynesian model. ${ }^{10}$ Figure 6 plots the probability of determinacy implied by our medium-sized model along with the probability implied by Coibion and Gorodnichenko's (2011) small-sized model.

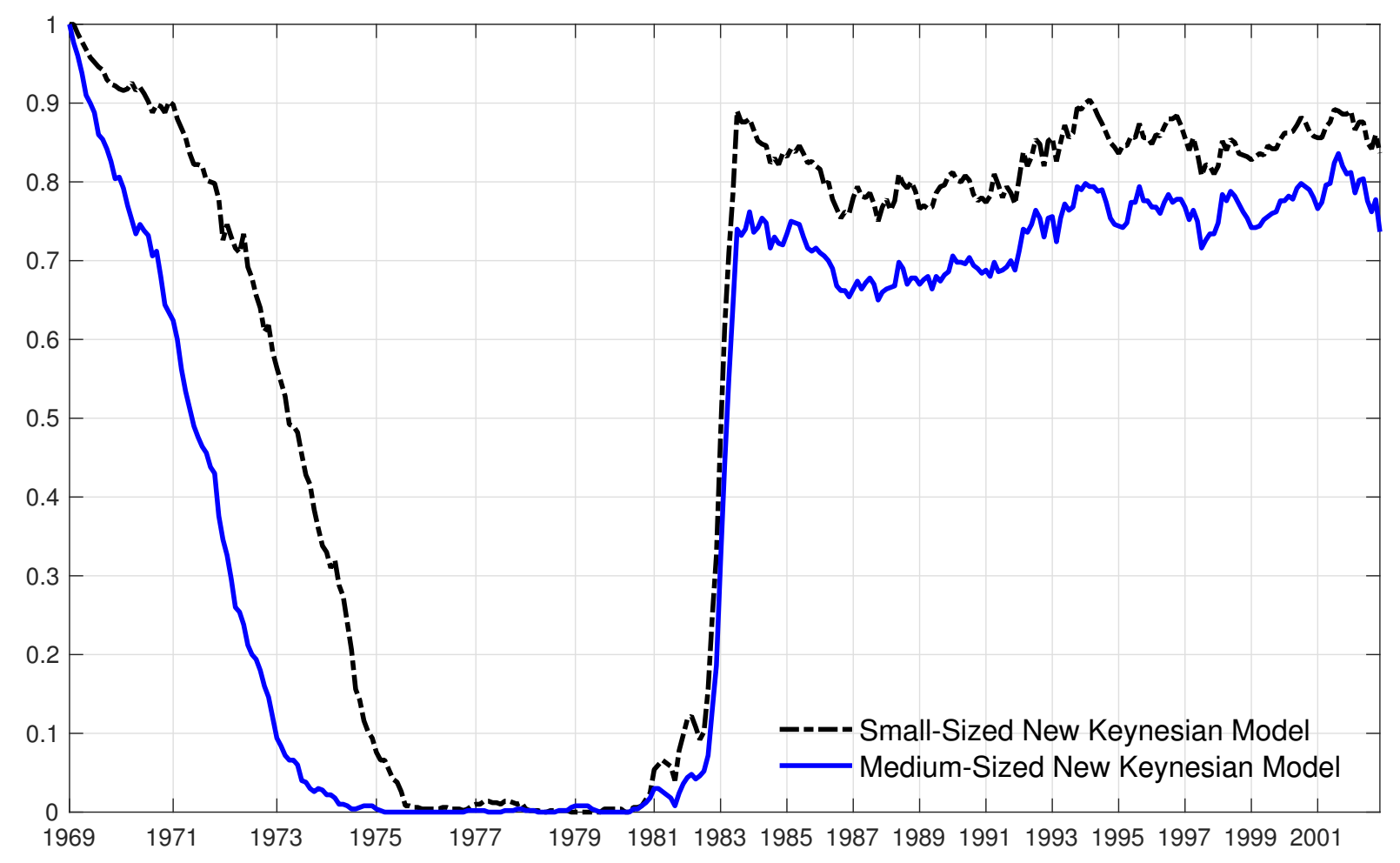

Figure 6: Probability of Determinacy Implied by New Keynesian Models

Overall, the probability of determinacy implied by the medium-sized New Keynesian model closely tracks that of the small-sized New Keynesian model. Hence, the small- and mediumsized models support the view, put forward by Clarida, Galí and Gertler (2000) and Lubik and Schorfheide (2004), that the U.S. economy was likely under indeterminacy during the 1970s and under determinacy during the post-Volcker era. Even so, the medium-sized model attributes a

\footnotetext{
${ }^{10}$ The remaining structural parameters are set to the posterior mode shown in Tables 2 and A.2.1.
} 
significantly lower probability of determinacy to the early 1970s, and it also attributes a somewhat lower probability of determinacy during the post-Volcker period. The probabilities of determinacy reported in Figure 6 encompass the estimation uncertainty associated with the level of trend inflation and with the monetary policy parameters. As a consequence, the simulation is not informative about the underlying sources affecting the probability of determinacy. Next, we will disentangle these effects by computing conditional probabilities of determinacy: the probability of determinacy conditional on trend inflation and the probability of determinacy conditional on monetary policy.

\subsection{Identifying the Role of Trend Inflation and of Monetary Policy}

To identify the role of monetary policy in shaping Figure 6, we compute the probability of determinacy conditional on trend inflation by fixing the level of trend inflation at either 2 or 4 percent and by drawing from the distribution of time-varying monetary policy parameters estimated by Coibion and Gorodnichenko (2011). The solid and the dashed-dotted lines in Panel (a) of Figure 7 exhibit big swings in the implied probability of determinacy in line with Figure 6. This implies that the systematic component of monetary policy is important: even if trend inflation had been equal to 2 percent, the probability of determinacy would have been lower than 0.2 around the mid-1970s. Moreover, a constant level of 4 percent trend inflation would lead to the same narrative as Figure 6: determinacy was very likely in the U.S. economy for the entire 1970s, up to post-1982 years. The relevance of monetary policy becomes even clearer if we compute the probability of determinacy at the same levels of trend inflation by drawing from the posterior distribution of the monetary policy rule estimated in Section 2. The dashed and dotted lines hover steadily around 0.9 , suggesting that neither the 2 percent nor the 4 percent trend inflation level implies a large probability of indeterminacy.

To identify the role of trend inflation in shaping Figure 6, we compute the probability of determinacy conditional on monetary policy by fixing the monetary policy parameters and by drawing from the distribution of the level of trend inflation estimated by Coibion and Gorodnichenko (2011). When conditioning on monetary policy, we consider three cases for the parameters associated with the monetary policy rule: (i) the estimates for the post-1982 period computed in Section 2; (ii) Coibion and Gorodnichenko's (2011) pre-1979 estimates; and (iii) Coibion and 


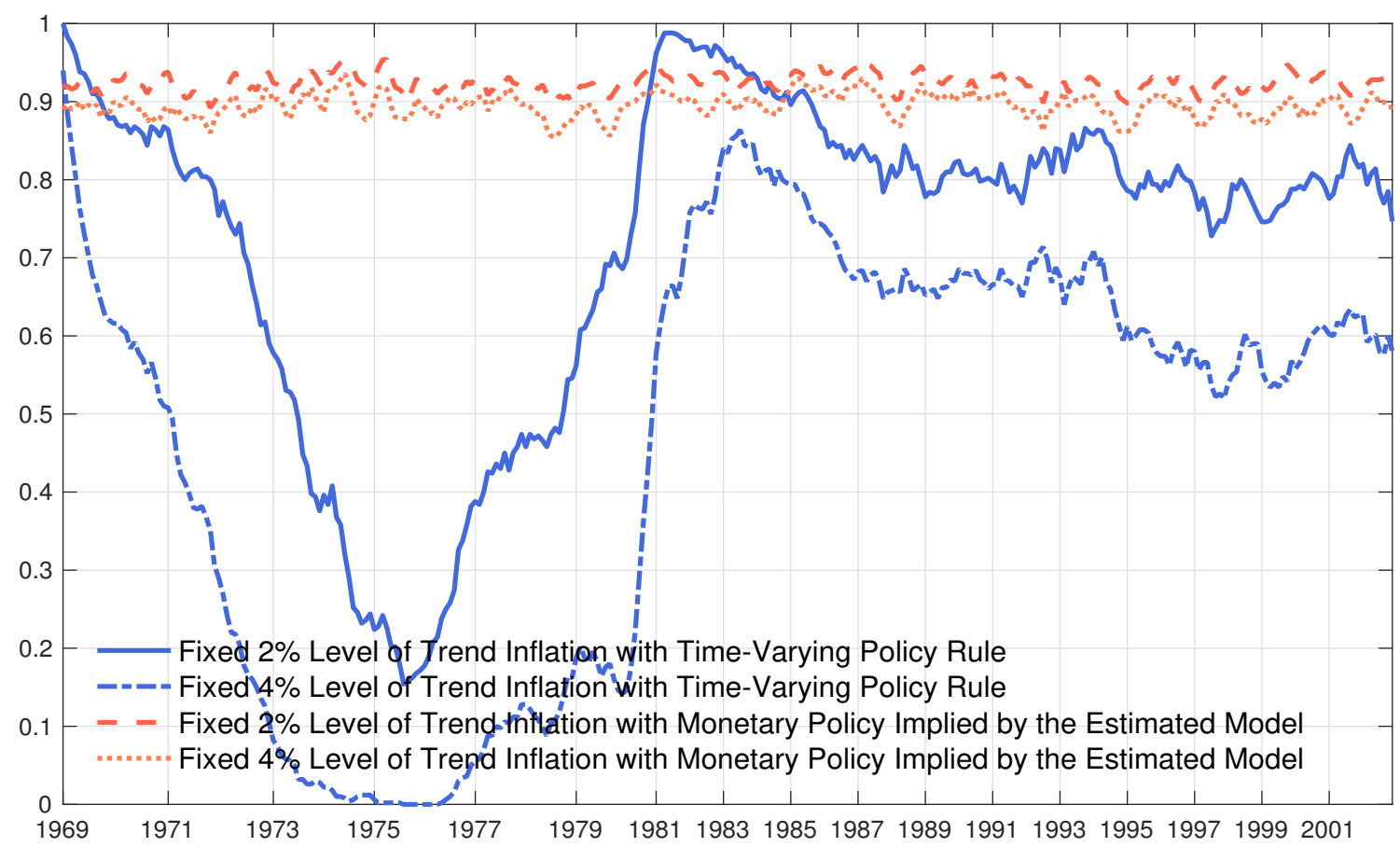

(a) The Role of Monetary Policy Given Trend Inflation

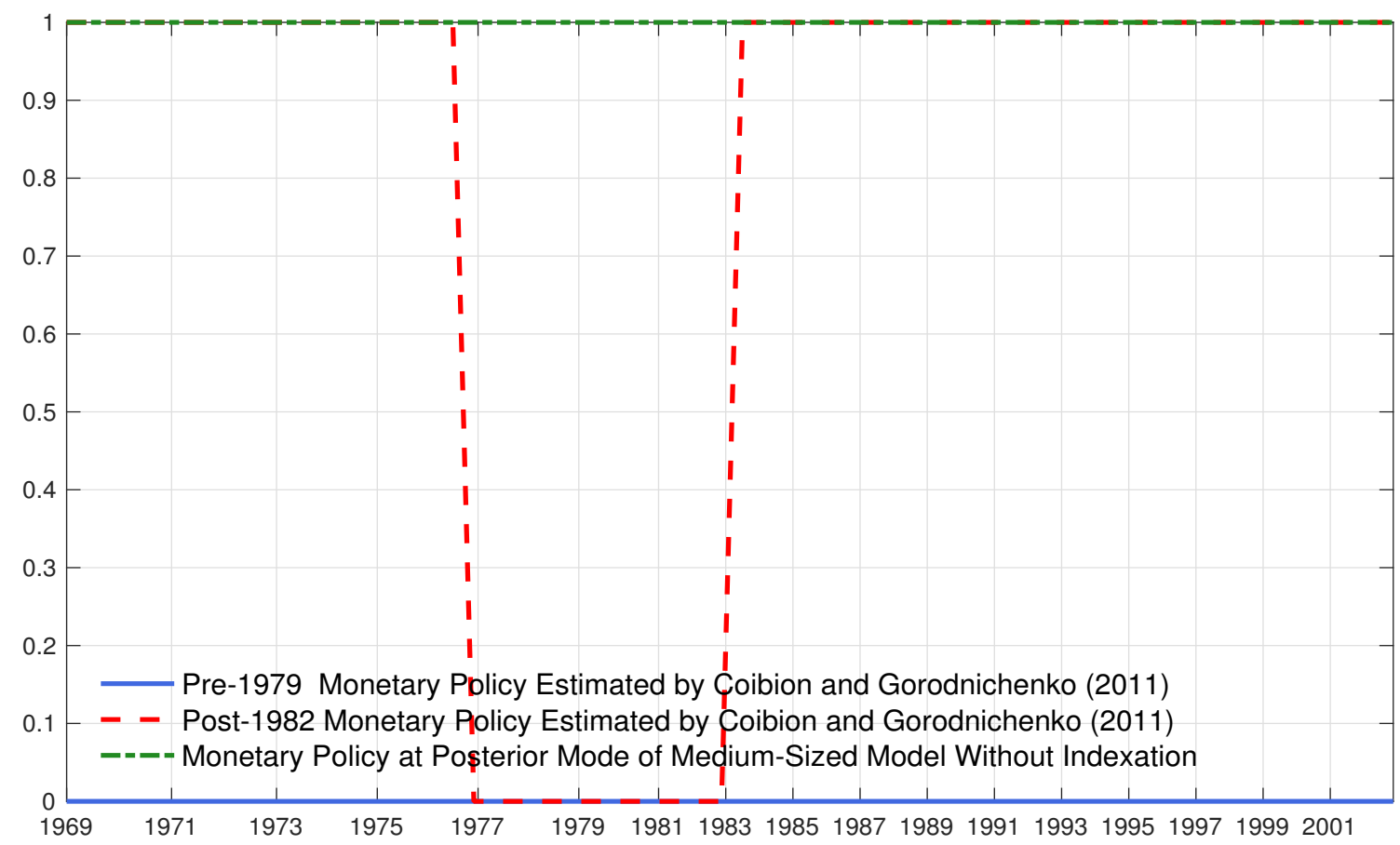

(b) The Role of Trend Inflation Given Monetary Policy

Figure 7: Interaction Between Monetary Policy and Trend Inflation

Gorodnichenko's (2011) post-1982 estimates. ${ }^{11}$ The solid line in Panel (b) of Figure 7 shows the

\footnotetext{
${ }^{11}$ Such point estimates are 2.2, 0.43/4, and 1.56 for the response to expected inflation, the output gap, and output growth, respectively; and 1.05 and -0.13 for the coefficients describing the degree of monetary policy inertia.
} 
probability of determinacy implied by our model when fixing the policy parameters at Coibion and Gorodnichenko's (2011) pre-1979 estimates. The probability of determinacy equals zero at the time of each FOMC meeting since 1969. The dashed line shows the probability of determinacy implied by our model when fixing the policy parameters at Coibion and Gorodnichenko's (2011) post-1982 estimates. This probability equals one at the time of most FOMC meetings except for those meetings that occurred between 1977 and 1983 when estimated trend inflation was above 6 percent. This indicates that conditional on passive monetary policy such as during the pre-1979 period, even moderate levels of trend inflation would cause indeterminacy. In contrast, conditional on active monetary policy such as during the post-1979 period trend inflation would cause indeterminacy only if it was above 6 percent.

As was the case with Panel (a), the relevance of monetary policy becomes even clearer when we use the estimates of Section 2. The dashed-dotted line shows the probability of determinacy conditional on the posterior mode of the monetary policy rule. The probability has always been equal to one at the time of every FOMC meeting since 1969. This is the case even during the period 1977-1983 when trend inflation is estimated to be higher than 6 percent (annualized) on average. $^{12}$

\subsection{Implications}

\subsubsection{The Role of Monetary Policy When Trend Inflation Equals 4 Percent}

The results in Sections 4.1 and 4.2 show the importance of the systematic component of monetary policy and suggest some caution in interpreting the results presented in Section 3.1. When one considers estimates of the monetary policy rule that take into account the information available to policymakers at the time of each FOMC meeting, the probability of determinacy at a level of trend inflation equal to 4 percent is remarkably lower than the probability reported in Section 3.1. Although the latter is near 0.9 , the former is only about 0.6 at the end of Coibion and Gorodnichenko's (2011) sample and close to 0.5 in the second part of the 1990s.

Figure 8 reveals the two main reasons behind this difference: the different values of the response

\footnotetext{
${ }^{12}$ In Figure $7 \mathrm{~b}$, the probabilities are always 0 or 1 , even though we take into account the uncertainty about the level of trend inflation. The fact that the probability is 0 or 1 simply means that the uncertainty in the level of trend inflation is small enough not to influence the probability of determinacy, given the policy rule in place. Thus, although important, the systematic component of monetary policy may not be enough to shield against indeterminacy at high levels of trend inflation.
} 
to the output gap and the higher uncertainty in Coibion and Gorodnichenko's (2011) estimates relative to ours. The figure shows the histograms implied by Coibion and Gorodnichenko's (2011) time-varying parameter draws for the post-1982 period (green bars) relative to the histograms obtained from our estimation (blue bars). Specifically, we compute a histogram for each of the parameters characterizing the systematic component of monetary policy: the response of the federal funds rate to inflation $\psi_{\pi}$, the response of the federal funds rate to the output gap $\psi_{y}$, the response of the federal funds rate to output growth $\psi_{g y}$, and the degree of monetary policy inertia $\rho \equiv \rho_{1}+\rho_{2}$.
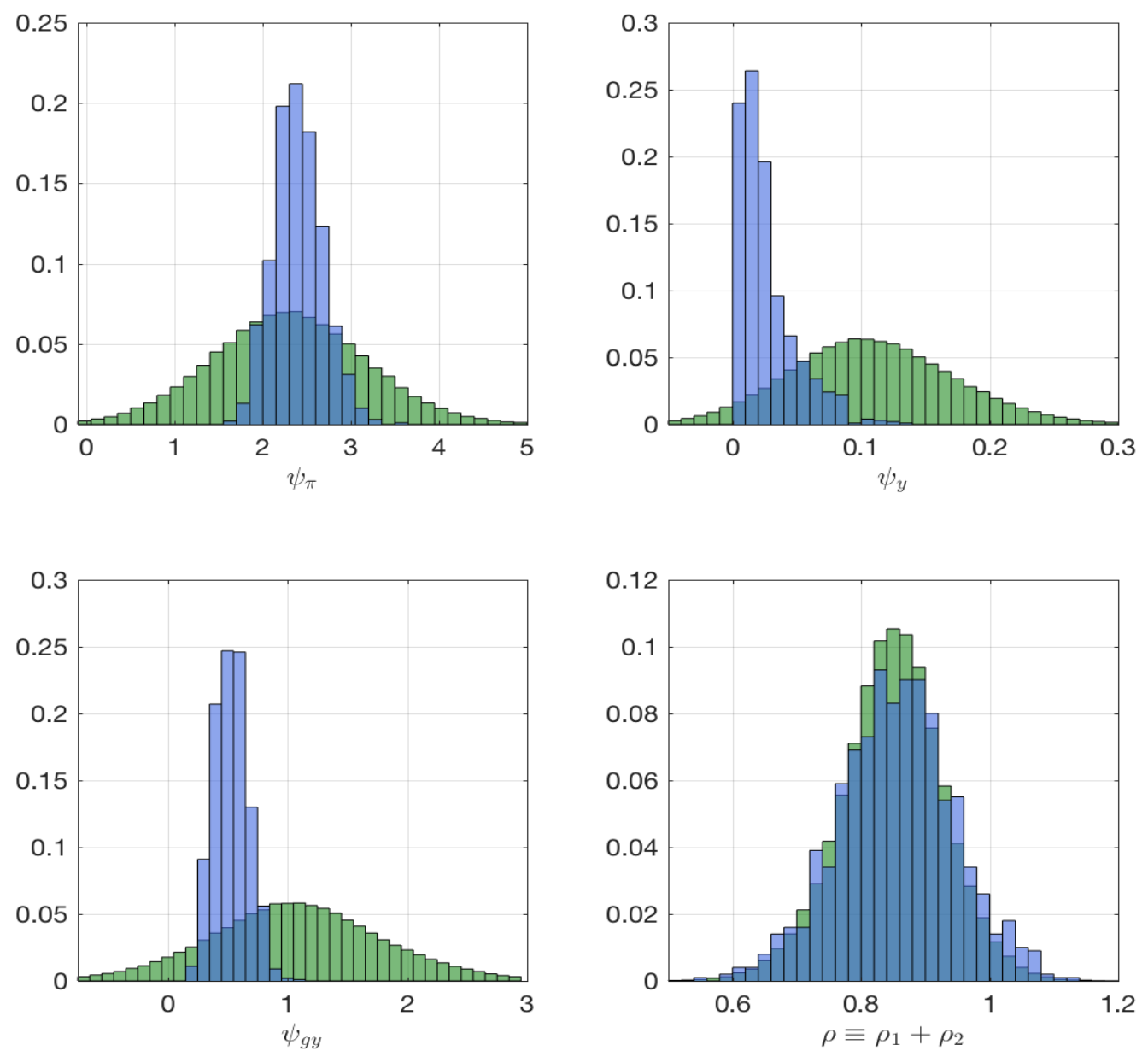

Coibion and Gorodnichenko's (2011) Post-1982 Monetary Policy Rule $\square$ Estimated model

Figure 8: Histograms of the Draws of Monetary Policy Coefficients

It is insightful to begin by examining the histograms for $\psi_{\pi}$ and $\psi_{y}$. The histogram for $\psi_{\pi}$ associated with our posterior estimates is concentrated around 2.4, and it assigns low probability to 
values below 2. The histogram for $\psi_{\pi}$ associated with Coibion and Gorodnichenko's (2011) estimates is also concentrated around 2.4, but it features a significantly larger variance. In particular, it assigns about 50 percent probability to values of $\psi_{\pi}$ that are below 2. The histogram for $\psi_{y}$ associated with our posterior estimates is quite concentrated around zero and assigns a negligible probability to values above 0.1. In contrast, the histogram for $\psi_{y}$ associated with Coibion and Gorodnichenko's (2011) estimates is almost symmetrically distributed around 0.1, and it exhibits a larger variance than the one implied by our estimates. About half of the parameter draws for $\psi_{y}$ are above $0.1 .^{13}$

The interaction of these histograms with the results in Section 3.2 is key to providing a rationale for our findings. As shown in Section 3.2, the medium-sized model is quite sensitive to the relation between trend inflation and $\phi_{y}$. In particular, Figure $5 \mathrm{~b}$ shows that when the level of trend inflation equals 4 percent and $\phi_{y}$ is larger than $0.1, \phi_{\pi}$ must be larger than 2 to achieve determinacy. Now consider the event $A=\left\{\left(\psi_{\pi}, \psi_{y}\right) \in \mathbb{R}_{+}^{2}: \psi_{\pi}>2\right.$ and $\left.\psi_{y}>0.1\right\}$. The probability attributed to event $A$ by the histograms associated with Coibion and Gorodnichenko's (2011) estimates is about 25 percent, while the probability attributed by the histograms associated with our posterior estimates is about zero. Hence, the parameters implied by our posterior estimates are more likely to induce determinacy.

In addition, while the responses of the federal funds rate to output growth implied by our posterior estimates are concentrated around 0.5 and assign zero probability to a zero response to output growth, Coibion and Gorodnichenko's (2011) time-varying parameter draws for the responses of the federal funds rate to output growth during the post-1982 period assign positive probability to a zero response to output growth. As shown in Panel (b) of Figure 5b, a positive response to output growth is a force toward determinacy conditional on positive responses to the output gap.

Altogether, the analysis above provides a rationale for the different probabilities of determinacy implied by our estimated model relative to those obtained when using real-time measures of monetary policy. In brief, relative to our posterior estimates, the distribution of the parameters estimated by Coibion and Gorodnichenko (2011) assigns a higher probability mass to strong

\footnotetext{
${ }^{13}$ We divide by 4 the value of $\phi_{y}$ in Coibion and Gorodnichenko's (2011) estimates because they estimate the Taylor rules using annualized rates, while the Taylor rule in the model is written in terms of quarterly rates. See footnote 20, p. 357 in Coibion and Gorodnichenko (2011).
} 
responses to the output gap and to small responses to expected inflation and output growth. The different distribution of the draws for $\phi_{\pi}$ and especially for $\phi_{y}$ explains most of the difference between the dotted and the dashed-dotted lines depicted in Figure 7a.

\subsubsection{The Role of Trend Inflation}

The analysis above supports the view that the systematic component of monetary policy is important to induce determinacy as put forward by Clarida, Galí and Gertler (2000) and Lubik and Schorfheide (2004). In this subsection, we show that trend inflation also plays a role supporting the view of Coibion and Gorodnichenko (2011).

To this end, we compare the probability of determinacy conditional on Coibion and Gorodnichenko's (2011) time-varying monetary policy when trend inflation is fixed at 4 percent (shown by the dashed-dotted line in Figure 7a) with the probability of determinacy conditional on Coibion and Gorodnichenko's (2011) time-varying monetary policy when trend inflation is allowed to vary (shown by the solid line in Figure 6). While the pattern of these conditional probabilities is similar, there are two notable differences during the period from 1977 until 1983 and during the 1990s. These differences provide useful insights on the role of trend inflation for determinacy.

Let's begin with the period 1977-1983. The probability of determinacy conditional on Coibion and Gorodnichenko's (2011) time-varying monetary policy when trend inflation is fixed at 4 percent increases from about 0.15 in 1980 to well above 0.5 in 1981. Because the level of trend inflation is fixed, this suggests that there is a structural change in the behavior of monetary policy around 1981 - note that the dashed-dotted line in Figure 7a is above 0.5 in 1981 and above 0.8 in 1983. This is in contrast with the probability of determinacy conditional on Coibion and Gorodnichenko's (2011) time-varying monetary policy when trend inflation is allowed to vary, which is very close to zero between 1981 and 1983. That is, the probability of determinacy does not increase despite the change in the systematic component of monetary policy discussed above. Note that the probability of determinacy is above 0.5 only after the Volcker disinflation of $1979-1982$ is accomplished. ${ }^{14}$ This indicates that the high levels of trend inflation observed during the period from 1981 until 1983 prevented the change in the systematic component of monetary policy from increasing the probability of determinacy. This is in line with the narrative in Coibion and Gorodnichenko (2011).

\footnotetext{
${ }^{14}$ In 1983, the trend inflation estimate fell below 6 percent.
} 
Let's now turn to the role played by trend inflation during the 1990s. The probability of determinacy conditional on Coibion and Gorodnichenko's (2011) time-varying monetary policy when trend inflation is fixed at 4 percent had decreased on average since 1984 and it is consistently below 0.6 during the late 1990s, see the dashed-dotted line in Figure 7a. In contrast, the probability of determinacy conditional on Coibion and Gorodnichenko's (2011) time-varying monetary policy when trend inflation is allowed to vary has decreased on average since 1987, reaching 0.75 during the early 1990s and hovering at that value for the remainder of the sample. The steady decline in the level of trend inflation during the 1990s explains this result. That is, the decline in trend inflation combined with active monetary policy tilted the U.S. economy toward a higher probability of determinacy. This effect is not present when we fix trend inflation at 4 percent, which explains the lower probability of determinacy.

\section{Conclusion}

We contribute to the debate on the costs and challenges associated with the recent proposal to increase the inflation target from 2 to 4 percent by studying the relation between trend inflation and determinacy in an off-the-shelf estimated New Keynesian model without indexation. Specifically, we focus on the challenge that increasing the inflation target poses to equilibrium determinacy. Our main result suggests that such an increase in the inflation target does not imply a significant risk of self-fulfilling fluctuations for the U.S. economy. Importantly, this result is conditional on the

estimated policy rule. When using real-time measures of the systematic component of monetary policy, the probability of determinacy drops significantly.

In our analysis, we abstract from price and wage indexation, and we assume a constant frequency of price adjustment. These are plausible assumptions for moderate levels of trend inflation; however, as trend inflation increases, for example, beyond 10 percent, firms are more likely to increase the frequency of price changes, see Gagnon (2009). This indicates that although models with state-dependent pricing could impact our conclusions, our findings provide a useful benchmark for the literature. 


\section{References}

Altig, D., L. J. Christiano, M. Eichenbaum, and J. Lindé (2011). Firm-Specific Capital, Nominal Rigidities and the Business Cycle. Review of Economic Dynamics 14(2), 225-247.

An, S. and F. Schorfheide (2007). Bayesian analysis of DSGE models. Econometric Reviews 26, $113-172$.

Ascari, G., E. Castelnuovo, and L. Rossi (2011). Calvo vs. Rotemberg in a Trend Inflation World: An Empirical Investigation. Journal of Economic Dynamics and Control 35, 1852-1867.

Ascari, G., L. Phaneuf, and E. Sims (2015). On the Welfare and Cyclical Implications of Moderate Trend Inflation. NBER Working Papers 21392, National Bureau of Economic Research, Inc.

Ascari, G. and T. Ropele (2009). Trend Inflation, Taylor Principle and Indeterminacy. Journal of Money, Credit and Banking 41(8), 1557-1584.

Ascari, G. and A. M. Sbordone (2014). The Macroeconomics of Trend Inflation. Journal of Economic Literature 52(3), 679-739.

Ball, L. (2014). The Case for a Long-Run Inflation Target of Four Percent. International Monetary Fund Working Paper 14(92).

Blanchard, O., G. Dell'Ariccia, and P. Mauro (2010). Rethinking Macroeconomic Policy. IMF Staff Position Note.

Blanco, J. A. (2017). Optimal Inflation Target in an Economy with Menu Costs and Zero Lower Bound. Working Paper.

Carlstrom, C. T. and T. S. Fuerst (2005). Investment and Interest Rate Policy: A Discrete Time Analysis. Journal of Economic Theory 123, 4-20.

Christiano, L., M. Eichenbaum, and C. Evans (2005). Nominal Rigidities and the Dynamic Effects of a Shock to Monetary Policy. Journal of Political Economy 113(1), 1-45.

Christiano, L. J., M. S. Eichenbaum, and M. Trabandt (2016). Unemployment and Business Cycles. Econometrica 84(4), 1523-1569. 
Clarida, R., J. Galí, and M. Gertler (2000). Monetary Policy Rules and Macroeconomic Stability: Evidence and Some Theory. Quarterly Journal of Economics 115, 147-180.

Coibion, O. and Y. Gorodnichenko (2011). Monetary Policy, Trend Inflation and the Great Moderation: An Alternative Interpretation. American Economic Review 101, 341-370.

Coibion, O. and Y. Gorodnichenko (2012). Why Are Target Interest Rate Changes so Persistent? American Economic Journal: Macroeconomics 4(4), 126-162.

Gagnon, E. (2009). Price Setting During Low and High Inflation: Evidence from Mexico. Quarterly Journal of Economics 124(3), 1221-1263.

Hirose, Y., T. Kurozumi, and W. Van Zandweghe (2017). Monetary Policy and Macroeconomic Stability Revisited. The Federal Reserve Bank of Kansas City, Research Working Paper.

Hornstein, A. and A. L. Wolman (2005). Trend Inflation, Firm-Specific Capital, and Sticky Prices. Federal Reserve Bank of Richmond Economic Quarterly 91(4), 57-83.

Justiniano, A. and G. E. Primiceri (2008). The Time-Varying Volatility of Macroeconomic Fluctuations. American Economic Review 98(3), 604-641.

Justiniano, A., G. E. Primiceri, and A. Tambalotti (2011). Investment Shocks and the Relative Price of Investment. Review of Economic Dynamics 14(1), 101-121.

Kiley, M. (2007). Is Moderate-to-High Inflation Inherently Unstable? International Journal of Central Banking 3(2), 173-201.

King, R. G. (2000). The New IS-LM Model: Language, Logic and Limits. Federal Reserve Bank of Richmond Economic Quarterly 86(3), 45-103.

Krugman, P. (2013). The Four Percent Solution. The New York Times.

Lubik, T. and F. Schorfheide (2004). Testing for Indeterminacy: An Application to U.S. Monetary Policy. American Economic Review 94(1), 190-217.

Orphanides, A. (2002). Monetary-Policy Rules and the Great Inflation. American Economic Review 92(2), 115-120. 
Orphanides, A. and J. C. Williams (2006). Monetary Policy with Imperfect Knowledge. Journal of the European Economic Association 4(2-3), 366-375.

Schmitt-Grohe, S. and M. Uribe (2012). What's News in Business Cycles. Econometrica 80(6), 2733-2764.

Smets, F. and R. Wouters (2007). Shocks and Frictions in U.S. Business Cycle: A Bayesian DSGE Approach. American Economic Review 97(3), 586-606.

Yun, T. (1996). Nominal Price Rigidity, Money Supply Endogeneity and Business Cycle. Journal of Monetary Economics 37, 345-370. 


\section{A Appendix}

\section{A.1 Data}

We estimate our model in Dynare 4.4.3. using Bayesian methods as described by An and Schorfheide (2007). We obtain 2 million draws from the posterior and discard the first 20 percent of them. The vector of observables contains data on inflation, growth rates of real GDP per capita, growth rates of real consumption per capita, growth rates of real investment per capita, growth rates of real wages, nominal interest rate, and deviations of hours worked from the steady-state.

The time series used to construct the vector of observables are retrieved from FRED, Federal Reserve Bank of St. Louis, and they are described as follows: (1) Real gross domestic product, billions of chained 2009 dollars, quarterly, seasonally adjusted annual rate; (2) Nominal gross domestic product, billions of dollars, quarterly, seasonally adjusted annual rate; (3) Personal consumption expenditures, nondurable goods, billions of dollars, quarterly, seasonally adjusted annual rate; (4) Personal consumption expenditures, services, billions of dollars, quarterly, seasonally adjusted annual rate; (5) Private residential fixed investment, billions of dollars, quarterly, seasonally adjusted annual rate; (6) Private nonresidential fixed investment, billions of dollars, quarterly, seasonally adjusted annual rate; (7) Effective federal funds rate, percent and annualized, quarterly, daily average aggregation, not seasonally adjusted; (8) Compensation per hour, nonfarm business sector, quarterly, seasonally adjusted, index 2009=100; (9) Civilian non-institutional population over 16, thousands of persons, quarterly; (10) GDP deflator $=\frac{(2)}{(1)}$; (11) Real per capita GDP $=\frac{(1)}{(9)} \frac{1 \mathrm{E}+9}{1 \mathrm{E}+3} ;(12)$ Real per capita consumption $=\frac{(3)+(4)}{(10)(9)} \frac{1 \mathrm{E}+9}{1 \mathrm{E}+3} ;(13)$ Real per capita investment $=\frac{(5)+(6)}{(10)(9)} \frac{1 \mathrm{E}+9}{1 \mathrm{E}+3} ;(14)$ Real wages $=\frac{(8)}{(10)} ;(15)$ Federal funds rate $=100\left(\left(1+\frac{(7)}{100}\right)^{\frac{1}{4}}-1\right) ;$ Average weekly hours, nonfarm business sector, quarterly, seasonally adjusted, index 2009=100; (17) Civilian employment over 16, thousands of persons, quarterly, average aggregate, seasonally adjusted; (18) Civilian non-institutional population over 16, thousands of persons; (19) Hours worked $=100 \ln \left(\frac{\frac{(16)(17) 1 \mathrm{E}+3}{100}}{(18) 1 \mathrm{E}+3}\right)$.

The growth rates of the GDP deflator, real per capita GDP, real per capita consumption, real per capita investment, and real wages are computed by transforming time series (10)-(14) to log differences in percentages. The nominal interest rate corresponds to time series (15). Finally, the deviations of hours worked from the steady-state correspond to time series (19), demeaned. 


\section{A.2 Structural Parameters}

In this section, we begin by discussing the estimated parameters shown in Table $2 .{ }^{1}$ For ease of exposition, we focus on the posterior mode. Consider the Taylor rule parameters. The response of the federal funds rate to one-period-ahead expected inflation $\psi_{\pi}$ equals 2.28. The response of the federal funds rate to the output gap $\psi_{y}$ and output growth $\psi_{g y}$ is 0.01 and 0.52 , respectively. The parameters describing the persistence of the Taylor rule $\rho_{R 1}$ and $\rho_{R 2}$ are 1.29 and -0.43 , respectively. While our estimates for the response of the federal funds rate to inflation and the degree of monetary policy inertia are in line with Coibion and Gorodnichenko (2011), the response of the federal funds rate to the output gap and output growth is smaller than the findings of Coibion and Gorodnichenko (2011). Even so, our estimates are in line with Coibion and Gorodnichenko (2011) in that both imply a higher response to output growth than to the output gap.

Turning to the deep structural parameters, the investment adjustment cost parameter $\kappa$ is equal to 3.98, which is between the posterior median reported by Justiniano and Primiceri (2008), 2.83, and the posterior mean reported by Smets and Wouters (2007), 6.23. The degree of habit persistence in our model is 0.82 , which is slightly larger than the posterior mean reported by Smets and Wouters (2007), i.e., 0.68, and the posterior median reported by Justiniano and Primiceri (2008), 0.77. The markup for intermediate goods $\left(\eta_{p}-1\right)^{-1}$ is equal to 0.26 , a tad larger than the value estimated by Justiniano and Primiceri (2008), 0.18. The markup for labor types $\left(\eta_{w}-1\right)^{-1}$ is equal to 0.20, similar to the value estimated by Justiniano and Primiceri (2008).

The inverse of the Frisch elasticity of labor supply $\tau$ is equal to 1.13, which is smaller than the posterior median reported by Justiniano and Primiceri (2008) and Smets and Wouters (2007) but close to that reported by Christiano, Eichenbaum and Trabandt (2016). The estimates for the parameters governing the frequency of price and wage adjustment $\nu_{p}$ and $\nu_{w}$ are 0.82 and 0.58, implying that firms adjust prices approximately once every 16 to 17 months, and wages are adjusted once every 7 to 8 months. Our estimates for $\nu_{p}$ and $\nu_{w}$ lie between the values estimated by Justiniano and Primiceri (2008) and the values estimated by Smets and Wouters (2007), respectively.

\footnotetext{
${ }^{1}$ Overall, the structural and the exogenous parameters exhibit good mixing properties. The convergence diagnostics are available upon request from the authors.
} 


\section{A.3 Exogenous Parameters}

\begin{tabular}{|c|c|c|c|c|c|c|c|}
\hline \multirow{2}{*}{ Parameters } & \multicolumn{4}{|c|}{ Posterior } & \multicolumn{3}{|c|}{ Prior } \\
\hline & Mode & Mean & 5 Percent & 95 Percent & Distribution & Mean & Std \\
\hline$\rho_{d}$ & 0.4801 & 0.4875 & 0.2326 & 0.7310 & Beta & 0.50 & 0.20 \\
\hline$\rho_{d_{L}}$ & 0.9679 & 0.9615 & 0.9318 & 0.9819 & Beta & 0.50 & 0.20 \\
\hline$\rho_{A}$ & 0.0954 & 0.1161 & 0.0354 & 0.2211 & Beta & 0.50 & 0.20 \\
\hline$\rho_{m I}$ & 0.7106 & 0.7014 & 0.5993 & 0.7930 & Beta & 0.50 & 0.20 \\
\hline$\rho_{G}$ & 0.9658 & 0.9645 & 0.9452 & 0.9819 & Beta & 0.50 & 0.20 \\
\hline$\sigma_{d}$ & 0.0202 & 0.0227 & 0.0134 & 0.0366 & Inverse Gamma & 0.001 & 2.00 \\
\hline$\sigma_{d_{L}}$ & 0.0208 & 0.0294 & 0.0168 & 0.0493 & Inverse Gamma & 0.001 & 2.00 \\
\hline$\sigma_{A}$ & 0.0053 & 0.0054 & 0.0048 & 0.0061 & Inverse Gamma & 0.001 & 2.00 \\
\hline$\sigma_{m I}$ & 0.0238 & 0.0247 & 0.0190 & 0.0331 & Inverse Gamma & 0.001 & 2.00 \\
\hline$\sigma_{R}$ & 0.0010 & 0.0010 & 0.0009 & 0.0012 & Inverse Gamma & 0.001 & 2.00 \\
\hline$\sigma_{G}$ & 0.0165 & 0.0168 & 0.0148 & 0.0191 & Inverse Gamma & 0.001 & 2.00 \\
\hline$\sigma_{o b s_{\pi}}$ & 0.0014 & 0.0015 & 0.0012 & 0.0018 & Inverse Gamma & 0.001 & 2.00 \\
\hline$\sigma_{o b s_{w}}$ & 0.0068 & 0.0069 & 0.0061 & 0.0078 & Inverse Gamma & 0.001 & 2.00 \\
\hline
\end{tabular}

Table A.2.1: Estimated Parameters of the Exogenous Processes 